\title{
Land subsidence due to groundwater extraction and tectonic activity in Pingtung Plain, Taiwan
}

\author{
Duc-Huy Tran and Shih-Jung Wang \\ Graduate Institute of Applied Geology, National Central University, Taoyuan City, 32001, Taiwan \\ Correspondence: Shih-Jung Wang (sjwang@ncu.edu.tw)
}

Published: 22 April 2020

\begin{abstract}
Pingtung coastal plain, located at the active convergent boundary between Philippine Sea Plate and Eurasian Plate, is one of the most active areas regarding tectonic deformation in Taiwan. Groundwater overpumping for aquaculture along the coast area of Pingtung plain induced a serious land subsidence problem for decades. How much land subsidence contributed by tectonic activity and groundwater pumping is a crucial issue for tectonic study and groundwater management in this area. This study collected the data in different fields and proposed a conceptual model to calculate the quantities of land subsidence caused by natural (tectonic) and human (pumping) factors. The data from the Global Positioning System (GPS) are used to illustrate the total subsidence concerning vertical displacement. A system called the multi-level compaction monitoring well (MCMW) is able to measure the vertical compaction in different depths from the earth surface to the depth of $200 \mathrm{~m}$. Two GPS stations, named CLON and FALI, close to two MCMWs, named Jiadong and Fangliao, are adopted for analysis The data during 2007 and 2016 taken from MCMWs and groundwater observation wells indicate that the compaction in the shallow depth should be mainly caused by groundwater over-pumping due to their high correlation coefficients (from 0.58-0.95). The difference of the vertical deformation between GPS and MCMW indicates that there is deformation beyond the depth within $200 \mathrm{~m}$. From the data and literature, the further vertical deformation should be due to tectonic activity associated with tectonic escape and extrusion of the Taiwan orogen with average vertical deformation from -3.0 to $-4.4 \mathrm{~mm}$. Therefore, the quantities of land subsidence contributed by local groundwater over-pumping and regional tectonic activities are successfully separated. The method and concept proposed in this study can be used in land subsidence quantification due to both tectonic activity and groundwater over-pumping.
\end{abstract}

\section{Introduction}

In southwest Taiwan, the Eurasian Plate is subducting with south-east direction beneath the Philippine Sea Plate at the Manila trench (Wu, 1978). In the previous studies with the moving speed of the Philippine Sea Plate of about $8.2 \mathrm{~cm} \mathrm{yr}^{-1}$, the force from the Philippine Sea Plate was much greater than that of the Eurasian plate, which collided with the east of Taiwan orogeny to create a series of thrust faults (Yu, 1997). Pingtung plain is located in South-western Taiwan, where the land use is mainly for agricultural and aquaculture. The unconsolidated sediments of the Pingtung plain form a basin and lie on the wedge-top depozone which form the main aquifer (Chiang et al., 2004). Covey (1986) and Chiang et al. (2004), they pointed out Pingtung plain is located in major piggyback basin of the wedge-top depozone where is lied on the foreland basin. Moreover, PlioceneQuaternary sedimentary from offshore to onshore have been deposited on the wedge-top depozone.

Taiwan is ranked 56th in the world regarding population with 667 person $\mathrm{km}^{-2}$ (United Nations World Prospects Report, 2017). With an economic development, the demand for water resources in Taiwan is increasing; however, the current water supply in Taiwan is insufficient compared with population density. Since the amount of surface water is inadequate to supply whole public water, groundwater exploitation becomes a must and causes land subsidence in the coastal plain, which leads to serious land subsidence (Chang et al., 2004; Hung et al., 2010; Wang, 2015). 


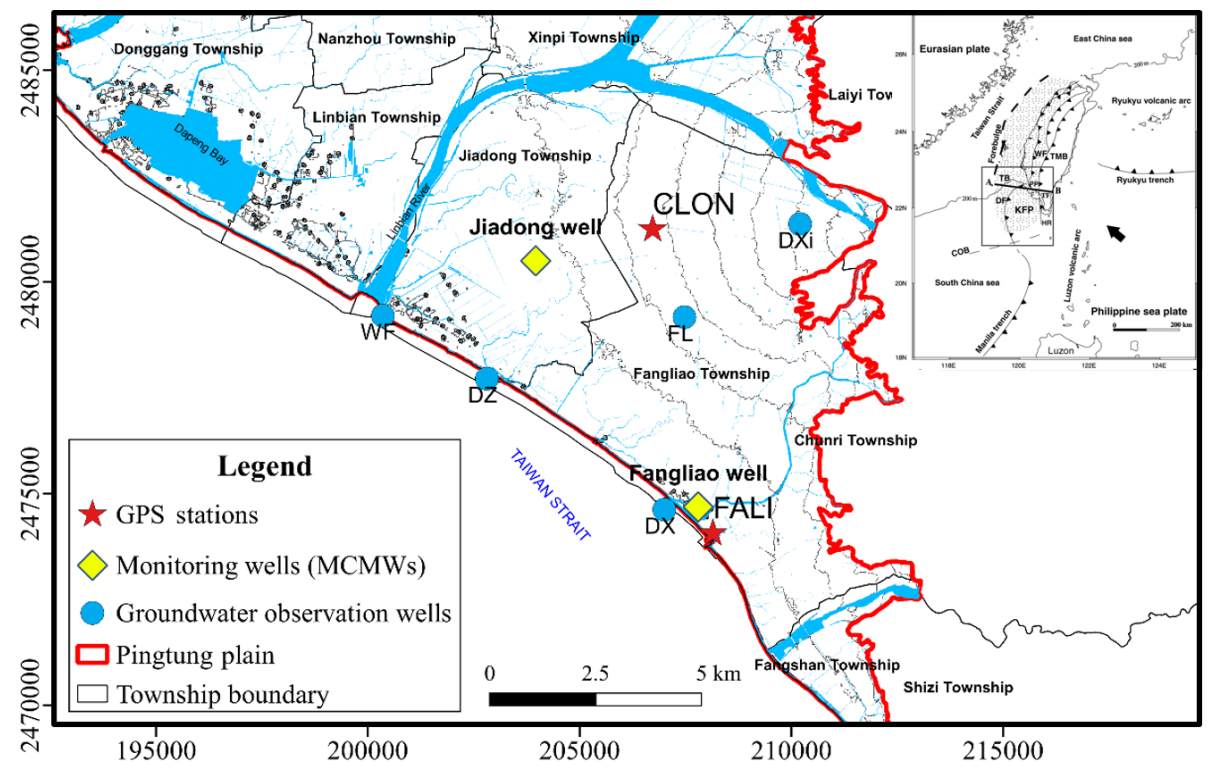

Figure 1. The distribution of monitoring system in the study area (Modified from Chiang et al., 2004).

The purpose of this research is to summarize information from the aforementioned research papers to propose a conceptual model to estimate how much land subsidence is due to the tectonic activities and non-tectonic activities. In this study, the data from global positioning system (GPS) is used to measure the vertical land deformation and a nearby system called the multi-level compaction monitoring well (MCMW) measures the compaction within $200 \mathrm{~m}$. These two survey data conducted from 2007 to 2016. Moreover, the correlation between the data of compaction monitoring wells, groundwater monitoring wells, and rainfall quantity are compared to realize the seasonal influence. After the data analysis, then knowing the area where the land surface changes occur and strongly affected by the change in the groundwater level, the elemental frequency analysis is proposed. This approach provides additional ideas on geological surveys as well as estimation of subsidence caused by plate tectonics in different sensitive tectonic regions in the world.

\section{Monitoring system}

Nowadays, the methodology for measuring land subsidence has been upgraded for years, and there are new studies to find out the past and present geological issues. In Taiwan, there are four techniques commonly used to observe land subsidence such as leveling, GPS, MCMW, and differential interferometric synthetic aperture radar (DInSAR). These techniques support each other in spatial and temporal domains. Three of them are used to measure the total subsidence consists of leveling, continuous GPS, and DInSAR. The one left measure compaction in different layers are MCMWs. Following Hung et al. (2010), the advantage of GPS is the daily sampling which provides sufficient data as well as high mobility and a quick survey. The next one is the MCMWs are used to measure the compaction of aquifer systems by anchoring several magnetic rings to aquifer systems at different depths with the advantage is its high accuracy of (about $1-5 \mathrm{~mm}$ ). The final technique, DInSAR is used to measure landscape changes by using many images at different times to create the interferogram images. The advantage is a spatial resolution, but there are various errors, especially for the atmospheric error which reduces the accuracy up to $2 \mathrm{~cm}$. Therefore, using survey data from continuous GPS and MCMW is proposed which are the powerful technique in this research. The distribution of monitoring system used in this study is shown in Fig. 1.

From the 10-year continuous leveling data, it has been shown that changing land surfaces at CLON station and Jiadong well is similar, so the CLON station is closest to Jiadong well. Besides that, there is a total of five wells for monitoring groundwater levels which were chosen in the study area. We divided into two areas of subsidence measuring in Jiadong township and Fangliao township, so the division of groundwater monitoring wells in two areas is also carried out for easy analysis. In Jiadong township area (Fig. 2), they include three groundwater observation wells named Wenfeng (WF), Dazhuang (DZ), Daxiang (DXi). In the Fangliao township area, the remaining two wells are named Fangliao (FL), and DeXing (DX). The groundwater observation wells have from the first aquifer to third aquifer and its distribution from the depth of 25 to $200 \mathrm{~m}$. In this study, the GPS and groundwater level data are based on the daily solution. However, the MCMW result is based on a monthly solution. 


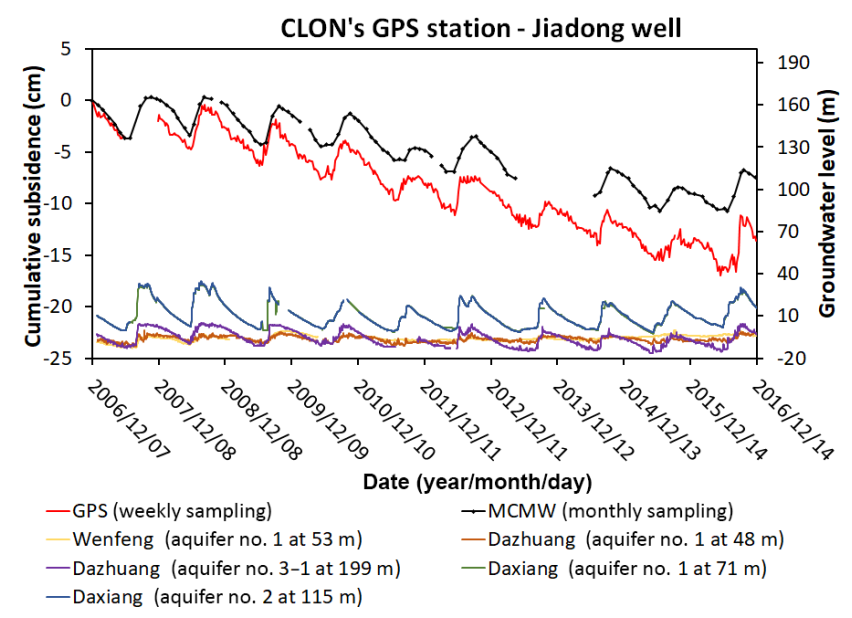

Figure 2. Cumulative subsidence of GPS data, MCMW data are in the left $y$-axis, and groundwater level variation, represented in right $y$-axis.

\section{Methodology}

A new idea with a simple equation to estimate subsidence in depths of below $200 \mathrm{~m}$. We rather suspect that the deep subsidence part is caused by natural impact. There are two main factors of the natural impact such as natural compaction and plate tectonics. Following the rock cycle, there are three main types of rocks: sedimentary, metamorphic, and igneous. Under the influence of nature, each type of rock when altered or destroyed will create loose materials or unconsolidated soil. That material would be sedimented respect to the timeconsuming transitions through geologic time is called natural compaction. Tectonic subsidence commonly occurs at a subduction zone, especially in Pingtung plain that is very active so it can easily lead to land subsidence. In the conceptual model, we separated into two main causes likely human and natural impact. Where a GPS station and MCMW device were established to measure the total subsidence and the changing of stratigraphic column within $200 \mathrm{~m}$. Thus, the equation to estimate land subsidence due to tectonic activities is proposed:

Tectonic subsidence $=$ Total subsidence

- Subsidence due to groundwater extraction

- Natural compaction

However, in the Geologist point of view, with the basic concept in geology when the physical and chemical weathering process forms the loose or weathering materials that have to change a type to another concerning geology time. From the unconsolidated soil to consolidated soil mechanism is a timeconsuming process. Thus, we use the data set for 10 years then the factor of natural compaction will not affect much. Besides, as mentioned in the previous section and the limit of the thickness of the alluvial deposit which is approximately smaller than $250 \mathrm{~m}$ (Jiang, 2018), we assume that the subsidence at the depth of more than $200 \mathrm{~m}$ equal to 0 caused by natural compaction. In addition, from the correlation coefficient matrix among each component that we know the relationship between groundwater and compaction in Multi-level compaction monitoring well (MCMW) is a positive relation. Whereas, the negative relation was shown in Table 1 between estimating tectonic and groundwater. Thus, the groundwater pumping in the depth greater than $200 \mathrm{~m}$ is impossible. Then, Eq. (1) will become:

Tectonic subsidence $=$ Total subsidence

- Subsidence due to groundwater extraction

\section{Results and discussion}

\subsection{Data analysis}

Figure 2 shows a variation of the time series under the seasonal effect. The most subsidence often falls during the dry season, so that the annual compactions in the dry season which calculated from the data of MCMW at both areas that range from -64.4 and $-40.1 \mathrm{~mm}$. In this study, we used the Pearson's $r$ correlation coefficient in order to analyse the correlation among data collected from subsidence observing wells and data from groundwater observation wells. In addition, since the same survey method was conducted in two different areas, it is significant to shed light on the correlation between them. To understand physical properties inside, we need to optimize the current data, hence analyzing the correlation of values is also necessary. Since calculation results were seasonally changed, especially subsidence data from both GPS stations and MCMW observing wells were deformed, there was a tendency of subsidence for a long time. Therefore, we utilized different methods and detrending method with the resampling data to analyse.

The correlation coefficients among the data from MCMWs and groundwater monitoring wells are high with the values from 0.58 to 0.95 , as listed in Table 1. That illustrated that MCMW can measure the land subsidence due to groundwater pumping from the Earth's surface to a depth of $200 \mathrm{~m}$. As mentioned previously, GPS station is established at the ground surface to measure the total subsidence that means that GPS system observes the whole vertical deformation including a movement of tectonic activity.

\subsection{Tectonic subsidence estimation}

The measurement period of MCMW device is one-month interval, while that of GPS system is daily interval. However, GPS system is very susceptible to atmospheric, so we used resampling and average method to analyze the data to avoid the errors. Therefore, subsidence data from GPS are 
Table 1. Correlation coefficient matrix between subsidence and groundwater level.

\begin{tabular}{|c|c|c|c|c|c|c|c|c|c|c|c|c|c|}
\hline$r$ value & $\begin{array}{r}\text { FALI } \\
\text { GPS }\end{array}$ & $\begin{array}{l}\text { Fangliao } \\
\text { MCMW }\end{array}$ & $\begin{array}{l}\text { Fangliao } \\
\text { Tectonic }\end{array}$ & DZ1 & DZ2 & WF & DXi1 & $\mathrm{DXi} 2$ & FL1 & FL2 & DX1 & $\mathrm{DX} 2$ & DX3 \\
\hline CLON GPS & 0.89 & 0.87 & 0.46 & 0.71 & 0.86 & 0.47 & 0.76 & 0.74 & 0.86 & 0.86 & 0.10 & 0.68 & 0.69 \\
\hline Jiadong MCMW & 0.66 & 0.86 & -0.02 & 0.82 & 0.92 & 0.58 & 0.78 & 0.77 & 0.90 & 0.90 & 0.04 & 0.73 & 0.71 \\
\hline Jiadong Tectonic & 0.56 & -0.18 & 0.66 & -0.03 & 0.09 & -0.08 & 0.15 & 0.16 & 0.12 & 0.13 & 0.13 & 0.07 & 0.11 \\
\hline DZ1 & 0.56 & 0.84 & -0.19 & 1.00 & 0.86 & 0.62 & 0.66 & 0.65 & 0.76 & 0.76 & 0.19 & 0.71 & 0.73 \\
\hline DZ2 & 0.61 & 0.91 & -0.27 & 0.86 & 1.00 & 0.58 & 0.93 & 0.92 & 0.98 & 0.97 & 0.30 & 0.86 & 0.87 \\
\hline WF & 0.47 & 0.58 & -0.06 & 0.62 & 0.58 & 1.00 & 0.49 & 0.49 & 0.49 & 0.50 & 0.04 & 0.38 & 0.47 \\
\hline DXi1 & 0.55 & 0.83 & -0.25 & 0.66 & 0.93 & 0.49 & 1.00 & 1.00 & 0.95 & 0.96 & 0.39 & 0.84 & 0.87 \\
\hline DXi2 & 0.54 & 0.83 & -0.25 & 0.65 & 0.92 & 0.49 & 1.00 & 1.00 & 0.95 & 0.95 & 0.40 & 0.84 & 0.87 \\
\hline FL1 & 0.62 & 0.91 & -0.34 & 0.76 & 0.98 & 0.49 & 0.95 & 0.95 & 1.00 & 1.00 & 0.27 & 0.86 & 0.89 \\
\hline FL2 & 0.62 & 0.91 & -0.28 & 0.76 & 0.97 & 0.50 & 0.96 & 0.95 & 1.00 & 1.00 & 0.24 & 0.86 & 0.89 \\
\hline DX1 & 0.01 & 0.18 & -0.15 & 0.19 & 0.30 & 0.04 & 0.39 & 0.40 & 0.27 & 0.24 & 1.00 & 0.33 & 0.30 \\
\hline DX2 & 0.60 & 0.90 & -0.26 & 0.71 & 0.86 & 0.38 & 0.84 & 0.84 & 0.86 & 0.86 & 0.33 & 1.00 & 0.91 \\
\hline DX3 & 0.68 & 0.95 & -0.18 & 0.73 & 0.87 & 0.47 & 0.87 & 0.87 & 0.89 & 0.89 & 0.30 & 0.91 & 1.00 \\
\hline
\end{tabular}

Note: DZ1, DZ2, WF, DXi1, DXi2, FL1, FL2, DX1, DX2, DX3 are the abbreviated name of groundwater observation wells.
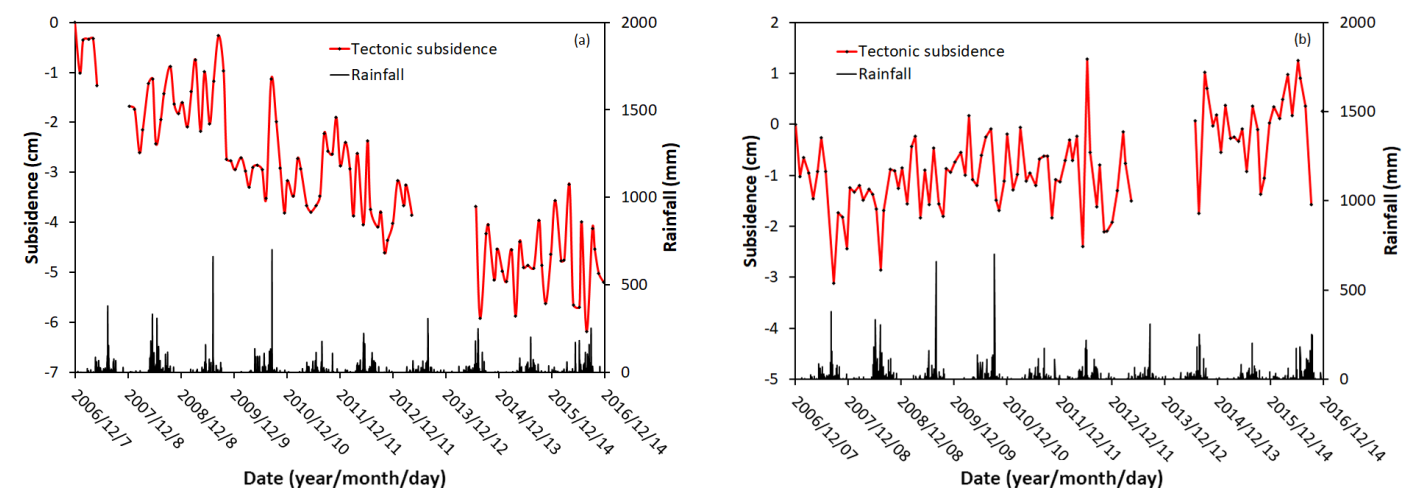

Figure 3. Monthly tectonic subsidence in (a) Jiadong area and (b) Fangliao area.

processed by using the weekly mean value cooperated with the resampling point. The calculation concept is that based on the date when MCMW data are collected, resample the point of GPS at the same date and averaged the seven values from before three days to after three days. This method is called the mid-point weekly sampling in this study.

After the pre-processes, Eq. (2) is adopted to calculate the tectonic subsidence, the results are shown in Fig. 3. The average deformation in Jiadong area and Fangliao area are -4.4 and $-3.0 \mathrm{~mm}$, respectively. The Pingtung area and the southeastern region of Taiwan in general must have a big creative stress from Philippine Sea Plate. With respect of time, Pingtung plain reaches the critical state, then lead to finding a way to release this stress. Tectonic escape accompanied with the transtensional deformation is occurred in the south-west direction (azimuth $243.9-245.7^{\circ}$ ) because of the free boundary at Taiwan strait. From these estimation results, the tectonic subsidence of coastal zone of Pingtung plain quite consistent with previous research which indicated the transtensional de- formation associated with the tectonic extrusion ( $\mathrm{Hu}$ et al., 2006).

\section{Conclusions}

MCMW is a system to monitor land subsidence due to groundwater over-pumping. The data collected from the groundwater monitoring wells and MCMW in Pingtung plain have the correlation coefficients varied from $0.58-0.95$, which express that the subsidence within $200 \mathrm{~m}$ is highly correlative to groundwater level variations and could be due to groundwater over pumping. Under the assumption of small influence of natural compaction, the vertical deformation induced by tectonic activity can be obtained using total subsidence minus subsidence within $200 \mathrm{~m}$. Then, both the vertical deformation contributed by natural factor of tectonic activity and human factor of groundwater over pumping can be estimated. For nature factor, the tectonic activity causes an average vertical deformation of -4.4 and $-3.0 \mathrm{~mm}$ in Jiadong and Fangliao areas, respectively. There are $70 \%$ 
and $82 \%$ of total subsidence are contributed by human factor. Comparing with the literature, the regional subsidence is caused by the transtensional deformation associated with the tectonic extrusion, then occurring tectonic escape in the south-west direction with azimuth 243.9-245.7 .

Data availability. The GPS data used in this study was obtained from the website of Academia Sinica, Taiwan, through http: //gps.earth.sinica.edu.tw/ (IESAS, 2007-2016). The groundwater level data can be obtained from the website of Water Resources Agency, Taiwan, through https://gweb.wra.gov.tw/wrhygis/ (Water Resources Agency, 2007-2016). However, the data of multi-level compaction monitoring well are not opened for public use at this moment, the raw data is belonged to Water Resources Agency, Taiwan.

Author contributions. The reference review, data analyses, figure and table preparations, and manuscript writing are done by DHT. SJW is the advisor, who provides the idea, data, comments, and suggestions for this research and revises the manuscript.

Competing interests. The authors declare that they have no conflict of interest.

Special issue statement. This article is part of the special issue "TISOLS: the Tenth International Symposium On Land Subsidence - living with subsidence". It is a result of the Tenth International Symposium on Land Subsidence, Delft, the Netherlands, 17-21 May 2021.

Acknowledgements. The authors would like to thank Professor Jyr-Ching $\mathrm{Hu}$ in National Taiwan University, Wei-Chia Hung in Green Environmental Engineering Consultant Co. LTD, and an anonymous reviewer for providing the valuable comments and suggestions to improve this research. The data provided by Academia Sinica, Taiwan, and Water Resources Agency, Taiwan, are much appreciated.

Financial support. This research has been supported by the Ministry of Science and Technology, Taiwan (grant no. MOST 1062116-M-008-023-MY3).

\section{References}

Chang, C. P., Chang, T. Y., Wang, C. T., Kuo, C. H., and Chen, K. S.: Land-surface deformation corresponding to seasonal groundwater fluctuation, determining by SAR interferometry in the SW Taiwan, Math. Comput. Simulat., 67, 351-359, 2004.

Chiang, C. S., Yu, H. S., and Chou, Y. W.: Characteristics of the wedge-top depozone of the southern Taiwan foreland basin system, Basin Res., 16, 65-78, 2004.

Covey, M.: The evolution of foreland basins to steady state: evidence from the western Taiwan foreland basin, Spec. Publ. Int. Ass. Sediment, 8, 77-90, 1986.

Hu, J. C., Chu, H. T., Hou, C. S., Lai, T. H., Chen, R. F., and Nien, P. F.: The contribution to tectonic subsidence by groundwater abstraction in the Pingtung area, southwestern Taiwan as determined by GPS measurements, Quat. Int., 147, 62-69, 2006.

Hung, W. C., Hwang, C., Chang, C. P., Yen, J. Y., Liu, C. H., and Yang, W. H.: Monitoring severe aquifer-system compaction and land subsidence in Taiwan using multiple sensors: Yunlin, the southern Choushui River Alluvial Fan, Environ. Earth Sci., 59, 1535-1548, 2010.

Institute of Earth Sciences, Academia Sinica (IESAS): Establishing an Automated GPS Processing and Analysis System to Provide an On-line Service for the Earth Sciences Research, available at: http://gps.earth.sinica.edu.tw/, 2007-2016.

Jiang, J. Y.: Shallow S-wave Velocity Structure of Pingtung Plain by Microtremor HVSR Simulation, M.S. Thesis, National Central University, 2018.

United Nations: World Population Prospects 2017 - Data Booklet (ST/ESA/SER.A/401), Department of Economic and Social Affairs, Population Division, 2017.

Wang, S. J.: Dimensional Upgrade Approach for Spatial-Temporal Fusion of Trend Series in Subsidence Evaluation, Entropy, 17, 3035-3052, 2015.

Water Resources Agency, Ministry of Economic Affairs, Taiwan: Hydrological year book of Taiwan, Republic of China, Part III Groundwater, 2007-2016.

Wu, F. T.: Recent tectonics of Taiwan, J. Phys. Earth, 26, S265S299, 1978.

Yu, S. B., Chen, H. Y., and Kuo, L. C.: Velocity field of GPS stations in the Taiwan area, Tectonophysics, 274, 41-59, 1997. 